\title{
ОПТИМИЗАЦИЯ ПСИХОЛОГО-ПЕДАГОГИЧЕСКИХ УСЛОВИЙ РАЗВИТИЯ НАУЧНО-ИССЛЕДОВАТЕЛЬСКИХ КОМПЕТЕНЦИЙ \\ В ПРОЦЕССЕ ПОДГОТОВКИ БУДУЩИХ ПЕРЕВОДЧИКОВ (НА ПРИМЕРЕ ДИСЦИПЛИНЫ «ОСНОВЫ ТЕОРИИ НЕМЕЦКОГО ЯЗЫКА»)
}

\author{
OPTIMIZATION OF PSYCHOLOGICAL AND PEDAGOGICAL CONDITIONS \\ FOR DEVELOPING SCIENTIFIC RESEARCH COMPETENCES \\ IN TRANSLATOR TRAINING \\ (ON THE EXAMPLE OF THE DISCIPLINE \\ "BASIC THEORY OF THE GERMAN LANGUAGE")
}

\author{
Е.В. Зеленина \\ E.V. Zelenina \\ Тульский государственный университет, \\ Россия, 300012, г. Тула, пр. Ленина, 92 \\ Tula State University, \\ 92 Prospect Lenina, Tula, 300012, Russia \\ E-mail: Zeleninagold@yandex.ru
}

\begin{abstract}
Аннотация
В условиях растущей востребованности на рынке труда выпускников, обладающих научным подходом, стремлением к применению и созданию инноваций, вопрос эффективного развития научно-исследовательских компетенций студентов высшей школы становится одним из приоритетных. Поиск решения данной проблемы актуализирует необходимость дополнения известных научно-педагогических трудов новыми научными изысканиями, основанными на современной специфике конкретных направлений подготовки в высшей школе. В связи с этим автором проанализированы труды отечественных и зарубежных ученых, в которых раскрываются сущность, содержание и компонентный состав компетенций, необходимых для эффективной научно-исследовательской деятельности, особенности организации исследовательского обучения. В результате исследования разработан комплекс психолого-педагогических условий развития компетенций научно-исследовательской деятельности в рамках преподавания дисциплины «Основы теории немецкого языка» и руководства курсовым проектированием по данной дисциплине при подготовке бакалавров лингвистики, целью которого является переход обучающихся на более высокий уровень сформированности компетенций научно-
\end{abstract} исследовательской деятельности.

\footnotetext{
Abstract

In the context of the accelerating pace of scientific and technological progress and the growing demand for graduates with a scientific attitude and an aspiration to apply and create innovations, the problem of the development of students' scientific research competences is becoming a priority. The search of the solution to this problem promotes a further scientific research based on the modern specifics of different university degree programmes in addition to well-known scientific works. For this reason the author has conducted a scientific research aimed at optimization of the development of future translators' scientific research competences. As a part of the research, the author has analyzed works of scholars from Russia and abroad which reveal the essence, the content and the components of competences necessary for the efficient scientific research, as well as describe special aspects of organization of scientifically-oriented learning process. As a result of the research the author has developed the complex of psychological and pedagogical conditions for developing scientific research competences in the process of teaching the
} 
discipline "Basic Theory of the German Language" to the bachelors of linguistics and research supervising of the students' course projects for this discipline aimed at students' transition to higher levels of scientific research competences. The theoretical and empirical data obtained as a result of the research allow to conclude that the use of the complex actively assists in the focused formation of students' scientific thinking and a scientific approach to solution of research tasks and, consequently, contributes to the optimization of the development of future translators' scientific research competences.

Ключевые слова: психолого-педагогические условия, компетенции, подготовка переводчиков, научно-исследовательская деятельность студентов, исследовательское обучение, курсовое проектирование, оптимизация, рефлексивность, инновационность, имидж исследователя, психологическая безопасность, профессиональная самореализация, интерактивные технологии, мониторинг.

Keywords: psychological and pedagogical conditions, competences, translator training, students' scientific research, scientifically-oriented learning, course projects, optimization, reflexivity, innovativeness, public image of scientific researchers, psychological safety, professional selfactualization, interactive technologies, monitoring.

\section{Введение}

В современном обществе формируются объективные условия, требующие развития у людей качеств, необходимых для полноценного участия в продвижении научнотехнического прогресса, создании и применении инноваций и одновременно для сохранения целостности структуры личности, ее гуманной сущности.

В связи с востребованностью на рынке труда выпускников, обладающих научным подходом, инновационным мышлением, вопрос эффективного развития научноисследовательских компетенций студентов высшей школы становится одним из приоритетных. Поиск решения данной проблемы актуализирует необходимость дополнения известных научно-педагогических трудов новыми научными изысканиями, основанными на современной специфике конкретных направлений подготовки в высшей школе.

Данное исследование посвящено вопросу оптимизации образовательного процесса на фоне необходимости учета быстро обновляющегося «банка» достижений научной и технической мысли. Отметим, что под оптимизацией в данном случае нами понимается комплексный научно-педагогический процесс, включающий поиск, выбор, внесение адаптационных изменений с учетом направления подготовки и реализацию наилучших из уже существующих научно обоснованных педагогических решений, нацеленных на усовершенствование развития научно-исследовательской деятельности обучающихся.

Целью исследования является разработка и апробация комплекса психологопедагогических условий развития компетенций научно-исследовательской деятельности бакалавров лингвистики, направленного на переход обучающихся на более высокий уровень сформированности компетенций научно-исследовательской деятельности.

\section{Научно-исследовательские компетенции как объект исследования}

Под компетенциями научно-исследовательской деятельности понимается спектр компетенций, указанных в федеральных государственных образовательных стандартах высшего образования, детализирующих свойства личности, формирование которых необходимо выпускникам для осуществления профессиональной деятельности.

Обратим внимание на определенные параллели между развитием компетенций научно-исследовательской деятельности и качеств, связанных с ними.

Акцентуация личностного осмысления прослеживается в определении исследовательской компетентности учащегося, предлагаемом Л.А. Казариной, которая трактует ее как «интегративное качество личности, предполагающее его готовность и способность к осуществлению исследовательской деятельности в той или иной области на основе сово- 
купности личностно-осмысленных знаний, умений, навыков, ценностных отношений» [Казарина, 2013, с. 197].

Комплексность содержания научно-исследовательской компетентности отражена в трудах В.П. Шестака и Н.В. Шестак, которые приходят к выводу, что это сложный синтез когнитивного, предметно-практического и личностного опыта, отличающийся многообразием когнитивных и некогнитивных компонентов [Шестак, Шестак, 2011].

Согласно модели обеспечения качества академических компетенций [Meijers et al., 2005], профиль будущего исследователя выглядит следующим образом: компетентен в одной или нескольких научных дисциплинах, в проведении исследования, в планировании, в кооперации и коммуникации; обладает научным подходом, базовыми интеллектуальными способностями; учитывает временной и социальный контекст.

Анализируя возможности операционализации состава научно-исследовательской деятельности обучающихся, немецкие ученые Ф. Тиль и Ф. Бёттхер [Thiel, Böttcher, 2014] выделяют информационно-поисковые, методологические, коммуникативные и рефлексивные компетенции, а также знания в научной отрасли.

К методическим решениям, позволяющим формировать компетенции научноисследовательской деятельности, с нашей точки зрения, можно отнести технологию исследовательского обучения [Шарипов, 2016]. Активизация учебной деятельности путем вовлечения обучающихся в поисковую работу творческого характера созвучна взглядам М.В. Кларина [Кларин, 1994] и Л. Хубера [Huber, 2013], исследовавшего смежное понятие «forschungsorientierte Lehre» («исследовательски-ориентированное обучение»).

Таким образом, проведенный анализ проблемного поля исследования в трудах зарубежных и отечественных педагогов раскрывает ряд важных особенностей компетенций научно-исследовательской деятельности.

\section{Результаты исследования}

Позволим себе поделиться результатами опыта в области оптимизации развития компетенций научно-исследовательской деятельности в процессе преподавания дисциплины «Основы теории немецкого языка» студентам направления «Лингвистика» Тульского государственного университета и, в частности, осуществления руководства курсовым проектированием по данной дисциплине с 2015 года по настоящее время. В своем научно-педагогическом поиске, основанном на изложенных ранее теоретикометодологических изысканиях ученых и анализе практического опыта, нам удалось выделить комплекс психолого-педагогических условий, способствующих развитию компетенций научно-исследовательской деятельности при изучении дисциплины «Основы теории немецкого языка». Данный комплекс условий неоднократно корректировался с учетом дополнения теоретической и научно-методологической базы и анализа постоянно обновляющихся данных о результативности научно-исследовательской деятельности студентов.

Рассмотрим каждое психолого-педагогическое условие комплекса, целью которого является переход обучающихся на более высокий уровень сформированности компетенций научно-исследовательской деятельности.

Первое условие - придание процессу обучения дисциплине «Основы теории немецкого языка» и руководству курсовым проектированием по данной дисциплине инновационно-исследовательского характера.

Формулируя данное условие, мы исходили из определений понятий «инновационность», «инновационный потенциал педагога», приводимых в трудах российских учёных Е.С. Быковой [2018], И.Д. Чечель [1998], С.Р. Яголковского [2011]. Являясь, по мнению Е.С. Быковой, одним из наиболее сложных объектов психолого-педагогических исследований, инновационность как черта личности объединяет различные качества: независи- 
мость мышления и поступков, чувство юмора, чувство красоты, сильную аргументацию, способность радоваться сложности и новизне информации, оригинальность, всестороннее изучение материала, гибкость [Быкова, 2018]. Проводя всесторонний анализ качества «инновационность», С.Р. Яголковский связывает его со способностями человека воспринимать новые идеи и технологии, а также осмысливать их и творчески дорабатывать [Яголковский, 2011, с. 98]. В связи с этим в нашем понимании инновационность относится к спектру качеств, связанных с умением мыслить нестандартно, оперируя при этом стандартными методологическими средствами. Именно эта характеристика позволяет исследователю привносить новизну в свою работу, идентифицировать уже известную информацию и, опираясь на нее, творчески реализовать исследовательский поиск, ориентированный на получение результатов, эффективно дополняющих существующую научную картину мира.

Таким образом, первое психолого-педагогическое условие предполагает организацию аудиторной и внеаудиторной работы педагога и студентов на основе интеграции актуально значимых и системно самоорганизующихся новообразований, возникающих на основе разнообразия инициатив и новшеств, которые становятся перспективными для эволюции образования и позитивно влияют на его развитие. Данное условие может быть обеспечено различными средствами:

1) с помощью развития инновационного потенцииала педагога как совокупности «социокультурных и творческих характеристик личности педагога, выражающей готовность совершенствовать педагогическую деятельность и наличие внутренних, обеспечивающих эту готовность средств и методов» [Чечель, 1998], включая желание и возможности развивать свои интересы и представления, искать собственные нетрадиционные решения. Поскольку, как отмечает И.Д. Чечель, наличие инновационного потенциала связано с творческой способностью генерировать и продуцировать новые представления и идеи, проектировать и моделировать их в практических формах, формах деятельности, а также с культурно-эстетической развитостью и образованностью, предполагающей интеллектуальную и эмоциональную развитость [Чечель, 1998], представляется целесообразным развитие преподавателя высшей школы по двойной траектории профессионального развития - как в направлении специфики преподаваемых дисциплин (в нашем случае дисциплин лингвистического цикла), так и в направлении совершенствования педагогического мастерства и выражения результатов данного развития, например, в создании авторских методических разработок, в форме научных публикаций;

2) с помощью формирования у студентов научной интерпретации преподаваемой дисииплины, в данном случае дисциплины «Основы теории немецкого языка», путем совместного с обучающимися выявления ее интегрального характера, специфических черт, взаимоотношений со смежными дисциплинами, подбора преподавателем научного материала для лекций и практических занятий, демонстрирующего теоретическую и практическую значимость, актуальность открытий в области данной дисциплины;

3) при помощи активного вовлечения студентов в научно-исследовательскую деятельность путем развития и удержания интереса к данному виду деятельности благодаря реализации в процессе преподавания дисциплины «Основы теории немецкого языка» и руководства курсовым проектированием уже существующих нестандартных подходов в образовании: включению в контекст занятий, в том числе и лекционных, компонентов, основанных на применении интерактивных методов и приемов обучения [Зеленина, 2017], предполагающих высокую степень самостоятельности обучающихся, их инициативность, развитие социальных навыков и творческих способностей, умение осуществлять информационно-исследовательский поиск. Это могут быть краткие дискуссии на основе просмотра видеосюжетов и презентаций с докладами о последних достижениях в изучаемой 
сфере, мозговые штурмы в области поиска новых направлений для исследований, составление алгоритмов и «дорожных карт» проведения исследований, организация конкурсов инновационных научных гипотез, разработка и решение лингвистических задач и т.д.

Например, благодаря проведению занятий по дисциплине «Основы теории немецкого языка» в необычных творческих формах, в частности в формате «Капсула времени», студентам предоставляется возможность почувствовать себя в роли исследователей разных эпох и по-своему решить стоящие перед ними задачи. Учебные занятия в таких формах содействуют росту интереса и мотивации к проведению научно-исследовательской деятельности.

Еще одним направлением, стимулирующим самостоятельный исследовательский поиск студентов, является организация занятий в форме мастер-классов, знакомящих с немецкоязычными национальными корпусами и базами данных, тренингов по применению корпусных технологий в исследованиях. Как показывает практика [Зеленина, 2016], использование корпусных данных позволяет индивидуализировать процесс проведения исследований, придает актуальность и новизну студенческим проектам.

Второе условие - придание процессу обучения дисциплине «Основы теории немецкого языка» и руководству курсовым проектированием формирующей рефлексивной направленности.

Роль рефлексивности как детерминантного свойства для структурной организации внутреннего мира человека в целом доказана многими учеными. Так, А.В. Карпов и T.А. Воронова констатируют наличие взаимосвязи высокого уровня рефлексии и способностей системы внутреннего мира личности к сохранению общей устойчивости и стабильности, самостоятельному обогащению, самоструктурированию, порождению системности [Карпов, Воронова, 2018].

В контексте проведения научных исследований рефлексивность может подразумевать различные рефлексивные практики, связанные с восприятием, осознанием процесса исследования и того, как данный процесс влияет на его результаты [Hardy at al., 2001]. Особенно интересным с точки зрения процесса обучения, представляется сочетание математической и психологической интерпретаций в понимании рефлексивности британскими учеными М. Аттиа и Дж. Эджем, которые определяют рефлексивность как непрерывное взаимное формирование исследователя исследованием и наоборот («on-going mutual shaping between researcher and research») [Attia, Edge, 2017]. Таким образом, на наш взгляд, может быть намечена личностно-ориентированная формирующая спираль применения рефлексивных практик в рамках исследовательски-ориентированного учебного процесса: исследование - рефлексия - приращение научного потенщиала личности исследователя исследование на более высоком уровне - рефлексия - приращение научного потенциила личности исследователя и т.д.

В связи с вышесказанным отметим, что предлагаемое нами второе психологопедагогическое условие развития компетенций научно-исследовательской деятельности нацелено на развитие у будущих переводчиков способностей к рефлексии, рефлексивности, являющихся важными факторами формирования научного стиля мышления, саморегуляции, и, как следствие, более успешной самореализации в научно-исследовательской деятельности.

Реализация данного условия возможна благодаря следующему:

1) внедрению в процесс осуществления исследования в рамках курсового проектирования по дисциплине «Основы теории немецкого языка» такой рефлексивной практики как ведение «Дневника исследователя» [Nadin, Cassel, 2006]. Рефлексия в рамках научного труда предполагает неоднократное осмысление и переосмысление ключевых позиций исследования, его методики, направления, критический анализ уже достигнутых теоретиче- 
ских и практических результатов, их интерпретацию, корректирование процесса исследования на основе уже очерченных перспектив и планов. Ведение дневника, в котором студент фиксирует свои мысли и идеи по поводу исследования, рекомендации руководителя проекта, позволяет создать подробную историю исследования, отражает маршруты, по которым осуществлялся научно-исследовательский поиск, помогает провести отбор научного материала для оформления финального варианта курсового проекта, отражает в целом развитие исследовательских качеств обучающегося. Относительно структуры «Дневника исследователя», его формы (на бумажном или электронном носителе, видео- или аудиозапись), наличия обязательных элементов содержания и степени детализированности его заполнения рекомендуем, опираясь на опыт руководства курсовыми проектами, предоставление студентам свободы выбора. Такой подход позволяет учесть индивидуальные особенности личности студентов различных психотипов, в том числе тех, для кого проведение исследования является формой стихийного творчества, и любая регламентация данного процесса может оказывать демотивирующий эффект;

2) систематическому мониторингу развития элементов компетенций научноисследовательской деятельности как комплексу диагностических процедур, включающему получение и обработку результатов обратной связи об итогах каждого из этапов исследовательской работы студентов (от выбора темы до предоставления финального варианта курсового проекта в печатном и электронном видах и защиты проекта) с целью своевременной коррекции приобретаемых элементов компетенций и представления рекомендаций по более эффективному их развитию. Очное обсуждение хода исследования, поиск решений возникающих научных проблем могут быть эффективно дополнены консультированием с помощью информационно-коммуникационных технологий, сети Интернет;

3) коллегиальному обсуждению и оцениванию группой экспертов результатов исследования: качества оформления курсового проекта, качества доклада студента, уровня защиты проекта с обязательной последующей аргументацией позиции экспертов. Без этой информации и успех, и неудача в плане проведения исследования приобретают однократный характер и не могут расцениваться как результат технологически выстроенной последовательности действий.

Третье условие - целенаправленное формирование у студентов положительного имиджа современного ученого-исследователя.

В основу данного условия положены идеи взаимосвязи результативности научноисследовательской работы отдельных ученых и научных учреждений в целом, приоритетности развития научного потенциала для государства, озвученные Дж. Абрамо, руководителем Лаборатории исследований в области оценки научной деятельности Института системного анализа и вычислительной техники (IASI-CNR) Национального научноисследовательского совета Италии. Считая инновации, основанные на научных исследованиях, источниками конкурентного преимущества на уровне как отдельных производств, так и целых государств, Дж. Абрамо отводит университетам важнейшую роль в генерировании и трансляции нового знания и новых научных достижений и, следовательно, в производственной конкуренции, экономическом росте и решении проблемы занятости [Абрамо, 2017, с. 112].

Таким образом, третье психолого-педагогическое условие мы связываем с развитием личности выпускника, ориентированной на научно-исследовательские достижения, профессиональное саморазвитие в сфере науки, осознающей перспективность правильно выстроенной научной деятельности для блага общества. Обеспечение данного условия возможно благодаря следующему:

1) трансляции студентам научно-исследовательского опыта (собственного, коллегпреподавателей, известных ученых) по осуществлению научно-исследовательского поис- 
ка. Результаты данного поиска могут быть представлены в виде научных статей, монографий, учебных пособий и т.д. Таким образом студенты получают наглядное представление о деятельности современных исследователей, ее результативности, возможностях применения ее достижений в практике преподавания и исследования, получают положительный профессиональный пример (что особенно важно для самоопределения молодых людей позднего подросткового возраста).

2) эффективному погружению студентов в современный научный мир с помощью ознакомления с его актуальными реалиями: например, национальной библиографической базой данных научного цитирования РИНЦ (Российский индекс научного цитирования), политематической реферативно-библиографической и наукометрической (библиометрической) базой данных Web of Science, единой базой данных, содержащей аннотации и информацию о цитируемости рецензируемой научной литературы, Scopus, фондами исследований, научными социальными сетями. Осознание студентами многообразия сфер для проявления научного потенциала способствует формированию панорамности и гибкости научного мышления обучающихся.

3) совместному с преподавателем проектированию перспективной траектории индивидуального развития молодого исследователя путем изучения будущих возможностей апробации и развития результатов проводимого обучающимися исследования: выступление на конференции, публикация в сборнике научных трудов, включение результатов исследования в последующие научные работы, участие в грантовых и стипендиальных программах и т.д. Таким образом намеченная перспективная траектория создает для обучающегося будущий научный задел, открывает потенциал, который он может успешно реализовать при эффективном развитии компетенций научно-исследовательской деятельности.

Четвертое условие - придание процессу развития компетенций научноисследовательской деятельности психологически благоприятного характера.

Необходимость включения данного педагогического условия в проектируемый комплекс продиктована, с нашей точки зрения, актуальностью соблюдения требований психологии безопасности образовательной среды как одной из отраслей безопасности личности.

В рамках педагогического процесса и процесса руководства научноисследовательской деятельностью студентов возникновение ситуаций, воспринимаемых как создающие состояние нестабильности, стресса, может быть связано со строгой детерминированностью в плане соблюдения сроков проведения исследований, необходимостью получения убедительных научных результатов в течение ограниченного периода времени, сложностью построения логики исследования и другими факторами. Как отмечают Н.В. Матяш и Т.А. Павлова, к числу важных психологических требований к личности для развития и сохранения ее психологической безопасности можно отнести способность к саморегуляции, рефлексивность, коммуникативные способности [Матяш, Павлова, 2018]. Однако не все участники учебного процесса обладают характеристиками, позволяющими противостоять негативному психологическому воздействию. В связи с этим представляется необходимой реализация мер, направленных на минимизацию эффекта негативного психологического воздействия на личность обучающегося и обучающего.

Формирование бережного отношения к личности обучающего и обучающегося в процессе развития компетенций научно-исследовательской деятельности достигается благодаря следующему:

1) приданию процессу руководства курсовыми проектами по дисциплине «Основы теории немецкого языка» субъект-субъектного характера, что предполагает организацию аудиторной и внеаудиторной работы как взаимодействия, сотрудничества педагога и студентов, нацеленного на переход обучающихся на более высокий уровень сформированности компетенций научно-исследовательской деятельности. Построение руководства кур- 
совым проектированием исходя из признания студента в качестве субъекта научноисследовательской деятельности, субъекта формирования компетенций, способствует совместности и скоординированности действий обучающего и обучающегося, укреплению взаимоуважения и признанию научной позиции преподавателя и студента;

2) организации на занятиях по дисциплине «Основы теории немецкого языка» презентаций научно-исследовательских кейсов коллегами-студентами старших курсов, в которых они делятся опытом проведения исследований, описывают особенности работы с теоретическим материалом, источники и методы анализа практического материала, рассказывают о возникших в процессе исследования трудностях и способах их преодоления. Такая практика апеллирует к эффекту положительного примера, проекции чужого продуктивного опыта на свою деятельность, оказывает стимулирующее воздействие;

3) включению в процесс проведения занятий по дисциплине «Основы теории немецкого языка» микроэлементов групповой психокоррекции эмоциональной сферы. Тренинговая компонента позволяет снизить эмоциональное напряжение участников педагогического процесса, адекватно оценивать ситуации, концентрироваться на положительных аспектах ведения научно-исследовательской деятельности. В частности, в нашей педагогической практике мы обращаемся к упражнениям тренинга снижения психоэмоционального напряжения, предлагаемым Т.В. Эксакусто для предотвращения возникновения хронической усталости и эмоционального выгорания: «Хорошее в плохом», «Золотая рыбка», «Оранжевые очки», «Рисую внутреннюю речь» [Эксакусто, 2010];

4) проведению преподавателем тренингов лингвистической креативности, нацеленных на создание атмосферы творческого поиска. Для реализации данного положения нами была разработана серия мини-тренингов лингвистической креативности с учетом интегральной специфики дисциплины «Основы теории немецкого языка». Каждый тренинг подразумевает совместное со студентами решение олимпиадной лингвистической задачи, связанной тематически с одним из изучаемых разделов дисциплины (например, «Фонетика», «Морфология»), и направлен на осмысление важных лингвистических понятий, таких как «фонема», «морфема», «падеж» и другие. Данные тренинги нацелены на создание позитивных эмоций, которыми сопровождается верное решение задачи, предложенное студентами или найденное с помощью подсказки преподавателя, и позволяют обучающимся глубже проникнуть в суть изучаемых явлений. Регулярное обращение к данным тренингам помогает выработать конструктивное отношение к ситуациям фрустрации в процессе исследования, вызванным временной неспособностью нахождения варианта решения на основе имеющейся в распоряжении информации, восприятию таких ситуаций как закономерного этапа творческого научно-исследовательского поиска.

\section{Заключение}

Таким образом, разработанный в результате проводимого нами исследования комплекс психолого-педагогических условий отражает трансформирующую сущность компетенций научно-исследовательской деятельности. Данный комплекс ориентирован на целенаправленное формирование научного мышления, научного подхода к решению научноисследовательских задач, нивелирование научного дилетантизма, характеризующегося однократностью успешного результата, благодаря чему способствует развитию компетенций научно-исследовательской деятельности при изучении дисциплины «Основы теории немецкого языка» и выполнении курсовых проектов по данной дисциплине.

Результаты, выводы и разработки не претендуют на исчерпывающее и окончательное решение проблемы развития компетенций научно-исследовательской деятельности, а представляют собой один из вариантов оптимизации данного процесса в рамках преподавания конкретной дисциплины в условиях высшей школы. 


\section{Список литературы}

1. Абрамо Дж. 2017. Библиометрическая оценка результативности научноисследовательской работы: к чему мы пришли? Пер. с англ. Л. Трониной. Вопросы образования, 1: $112-127$.

2. Быкова Е.С. 2018. Психологическое исследование характеристик инновационной личности: теория и опыт. Человеческий фактор: Социальный психолог, 1 (35): 218-228.

3. Зеленина Е.В. 2016. К вопросу использования лингвистического материала Национального корпуса русского языка при разработке компетентностно-ориентированных заданий (на примере изучения «ложных друзей переводчика»). Ученые записки Орловского государственного университета. Серия: Гуманитарные и социальные науки, 1 (70): 170-175.

4. Зеленина Е.В. 2017. Лекция с интерактивным компонентом. Ученые записки Орловского государственного университета. Серия: Гуманитарные и социальные науки, 2 (75): 242-248.

5. Казарина Л.А. 2013. Показатели сформированности исследовательской компетентности учащихся профильных классов. Вестник Томского государственного педагогического университета, 7 (135): 196-201.

6. Карпов А.В., Воронова Т.А. 2018. Рефлексивность как детерминанта структурной организации внутреннего мира человека. Историческая и социально-образовательная мысль, 10 (3/2): 104-110.

7. Кларин М.В. 1994. Инновационные модели обучения в зарубежных педагогических поисках. М., Арена, 224 с.

8. Матяш Н.В., Павлова Т.А. 2018. Устойчивость личности к негативному психологическому воздействию как проблема психологической безопасности личности. В кн.: Организационные и психолого-педагогические проблемы безопасности личности и социальной среды. Материалы Международной научно-практической конференции (Брянск, 25-26 апреля 2018 г.). Под ред. Н.В. Матяш, О.А. Карнеевой, Р.К. Карнеева, Г.Ф. Голубевой. Брянск, Брянский государственный университет имени академика И.Г. Петровского: 63-69.

9. Чечель И.Д. 1998. Управление исследовательской деятельностью педагога и учащегося в современной школе. М., Сентябрь, 144 с.

10. Шарипов Ф.В. 2016. Технология исследовательского обучения. Международный журнал экспериментального образования, 5: 371-374.

11. Шестак В.П., Шестак Н.В. 2011. Формирование научно-исследовательской компетенции и «академическое письмо». Высшее образование в России, 12: 115-119.

12. Эксакусто Т.В. 2010. Практикум по групповой психокоррекции: тренинги, упражнения, ролевые игры. Ростов н/Д., Феникс, 339 с.

13. Яголковский С.Р. 2011. Психология инноваций: подходы, модели, процессы. М., Изд. дом Высшей школы экономики, $271 \mathrm{c}$.

14. Attia M., Edge J. 2017. Be(com)ing a reflexive researcher: a developmental approach to research methodology. Open Review of Educational Research, 4 (1): 33-45.

15. Hardy C., Phillips N., Clegg S. 2001. Reflexivity in organization and management theory. Human Relations, 54 (5): 531-60.

16. Huber L. 2013. Forschungs- und Berufsorientierung in der akademischen Lehre. Redemanuskript. Zürich, 11 Available at: https:/gabi-reinmann.de/wpcontent/uploads/2013/12/Vortrag_Zuerich_Dez2013.pdf (accessed: 03.05.2019).

17. Meijers A.W.M., Borghuis V.A.J., Mutsaers E.J.P.J., Overveld van C.W.A.M., Perrenet J.C. 2005. Criteria voor academische bachelor en master curricula = Criteria for academic bachelor's and master's curricula. 2e, gew. dr. ed. Eindhoven: Technische Universiteit Eindhoven, 24. Available at: https://pure.tue.nl/ws/portalfiles/portal/2008910/591930E.pdf (accessed: 03.05.2019).

18. Nadin S., Cassel C. 2006. The use of a research diary as a tool for reflexive practice: Some reflections from management research. Qualitative Research in Accounting \& Management, 3 (3): 208-217.

19. Thiel F., Böttcher F. 2014. Modellierung fächerübergreifender. Forschungskompetenzen. In: Neues Handbuch Hochschullehre. Berlin: Raabe: 109-124 Available at: https://www.fuberlin.de/sites/fol/_media/Thiel_Boettcher_2014_Modellierung-faecheruebergreifender-

Forschungskompetenzen.pdf (accessed: 03.05.2019). 


\section{References}

1. Abramo G. 2017. Bibliometricheskaja ocenka rezul'tativnosti nauchno-issledovatel'skoj raboty: k chemu my prishli? [Bibliometric Evaluation of Research Performance: Where Do We Stand?]. Voprosy obrazovanija, 1: 112-127.

2. Bykova E.S. 2018. Psihologicheskoe issledovanie harakteristik innovacionnoj lichnosti: teorija i opyt [A psychological study of the characteristics of an innovative personality: theory and experience]. Chelovecheskij faktor: Social'nyj psiholog. 1 (35): 218-228.

3. Zelenina E.V. 2016. K voprosu ispol'zovanija lingvisticheskogo materiala Nacional'nogo korpusa russkogo jazyka pri razrabotke kompetentnostno-orientirovannyh zadanij (na primere izuchenija «lozhnyh druzej perevodchika») [On using Russian National Corpus data in constructing competencebased tasks (on the example of translator's false friends learning)]. Uchenye zapiski Orlovskogo gosudarstvennogo universiteta. Serija: Gumanitarnye i social'nye nauki, 1 (70): 170-175.

4. Zelenina E.V. 2017. Lekcija s interaktivnym komponentom [Lecture with an interactive component]. Uchenye zapiski Orlovskogo gosudarstvennogo universiteta. Serija: Gumanitarnye i social'nye nauki. 2 (75): 242-248.

5. Kazarina L.A. 2013. Pokazateli sformirovannosti issledovatel'skoj kompetentnosti uchashhihsja profil'nyh klassov [Formed research competence indicators of profile class learners]. Vestnik Tomskogo gosudarstvennogo pedagogicheskogo universiteta, 7 (135): 196-201.

6. Karpov A.V., Voronova T.A. 2018. Refleksivnost' kak determinanta strukturnoj organizacii vnutrennego mira cheloveka [Reflexivity as determinant of structural organization of man's inner world]. Istoricheskaja i social'no-obrazovatel'naja mysl', 10 (3/2): 104-110.

7. Klarin M.V. 1994. Innovacionnye modeli obuchenija v zarubezhnyh pedagogicheskih poiskah. M., Arena, $224 \mathrm{p}$.

8. Matjash N.V., Pavlova T.A. 2018. Ustojchivost' lichnosti k negativnomu psihologicheskomu vozdejstviju kak problema psihologicheskoj bezopasnosti lichnosti [Resistance of the personality to negative psychological impact as problem of psychological safety of the personality]. In: Organizacionnye i psihologo-pedagogicheskie problemy bezopasnosti lichnosti i social'noj sredy [Organizational and psychological-pedagogical problems of personal security and social environment]. Materialy Mezhdunarodnoj nauchno-prakticheskoj konferencii (Bryansk, 25-26 aprelya 2018 g.). Pod red. N.V. Matyash, O.A. Karneevoy, R.K. Karneeva, G.F. Golubevoy. Bryansk, Bryanskiy gosudarstvennyy universitet imeni akademika I.G. Petrovskogo: 63-69.

9. Chechel' I.D. 1998. Upravlenie issledovatel'skoj dejatel'nost'ju pedagoga i uchashhegosja v sovremennoj shkole [Management of research activities of a teacher and a student in a modern school]. M., Sentjabr', 144 p.

10.Sharipov F.V. 2016. Tehnologija issledovatel'skogo obuchenija [Research Education Technology]. Mezhdunarodnyj zhurnal jeksperimental'nogo obrazovanija, 5: 371-374.

11.Shestak V.P., Shestak N.V. 2011. Formirovanie nauchno-issledovatel'skoj kompetencii i «akademicheskoe pis'mo» [Research competence and academic writing]. Vysshee obrazovanie v Rossii, 12: $115-119$.

12.Jeksakusto T.V. 2010. Praktikum po gruppovoj psihokorrekcii: treningi, uprazhnenija, rolevye igry [Workshop on group psychocorrection: trainings, exercises, role-playing games]. Rostov n/D., Feniks, 339 p.

13.Jagolkovskij S.R. 2011. Psihologija innovacij: podhody, modeli, process [Psychology of innovation: approaches, models, processes]. M., Izd. dom Vysshej shkoly jekonomiki, $271 \mathrm{p}$.

14.Attia M., Edge J. 2017. Be(com)ing a reflexive researcher: a developmental approach to research methodology. Open Review of Educational Research, 4 (1): 33-45.

15.Hardy C., Phillips N., Clegg S. 2001. Reflexivity in organization and management theory. Human Relations, 54 (5): 531-60.

16. Huber L. 2013. Forschungs- und Berufsorientierung in der akademischen Lehre. Redemanuskript. Zürich, 11 Available at: https://gabi-reinmann.de/wpcontent/uploads/2013/12/Vortrag_Zuerich_Dez2013.pdf (accessed: 03.05.2019).

17.Meijers A.W.M., Borghuis V.A.J., Mutsaers E.J.P.J., Overveld van C.W.A.M., Perrenet J.C. 2005. Criteria voor academische bachelor en master curricula $=$ Criteria for academic bachelor's and mas- 
ter's curricula. 2e, gew. dr. ed. Eindhoven: Technische Universiteit Eindhoven, 24. Available at: https://pure.tue.nl/ws/portalfiles/portal/2008910/591930E.pdf (accessed: 03.05.2019).

18. Nadin S., Cassel C. 2006. The use of a research diary as a tool for reflexive practice: Some reflections from management research. Qualitative Research in Accounting \& Management, 3 (3): 208-217.

19.Thiel F., Böttcher F. 2014. Modellierung fächerübergreifender. Forschungskompetenzen. In: Neues Handbuch Hochschullehre. Berlin: Raabe: 109-124 Available at: https://www.fuberlin.de/sites/fol/_media/Thiel_Boettcher_2014_Modellierung-faecheruebergreifender-

Forschungskompetenzen.pdf (accessed: 03.05.2019).

\section{Ссылка для цитирования статьи For citation}

Зеленина Е.В. 2020. Оптимизация психолого-педагогических условий развития научноисследовательских компетенций в процессе подготовки будущих переводчиков (на примере дисциплины «Основы теории немецкого языка»). Вопросы журналистики, педагогики, языкознания, 39 (1): 47-57. DOI: 10.18413/2712-7451-2020-39-1-47-57

Zelenina E.V. 2020. Optimization of psychological and pedagogical conditions for developing scientific research competences in translator training (on the example of the discipline "Basic theory of the German language"). Issues in Journalism, Education, Linguistics, 39 (1): 47-57 (in Russian). DOI: $10.18413 / 2712-7451-2020-39-1-47-57$ 